\title{
Article
}

\section{Editorial to special edition commemorating the work of Professor Stephen Bax}

Thomas, Michael and Motteram, Gary

Available at http://clok.uclan.ac.uk/28321/

Thomas, Michael ORCID: 0000-0001-6451-4439 and Motteram, Gary (2019)

Editorial to special edition commemorating the work of Professor Stephen

Bax. System . ISSN 0346-251X

It is advisable to refer to the publisher's version if you intend to cite from the work. http://dx.doi.org/10.1016/j.system.2019.04.002

For more information about UCLan's research in this area go to http://www.uclan.ac.uk/researchgroups/ and search for <name of research Group>.

For information about Research generally at UCLan please go to http://www.uclan.ac.uk/research/

All outputs in CLoK are protected by Intellectual Property Rights law, including Copyright law. Copyright, IPR and Moral Rights for the works on this site are retained by the individual authors and/or other copyright owners. Terms and conditions for use of this material are defined in the policies page.

\section{CLoK}

Central Lancashire online Knowledge www.clok.uclan.ac.uk

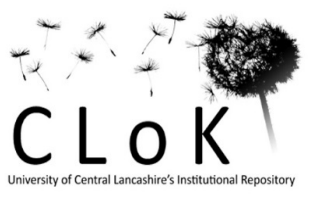




\section{Editorial for the Special Edition Commemorating the Work of Stephen Bax}

Michael Thomas

Gary Motteram

The teaching and research interests of Professor Stephen Bax, a leading scholar in computer-assisted language learning (CALL) who died in 2017, spanned a number of areas, including the normalization of digital technologies, eye-tracking and learners' cognitive processing in intertextual reading and reading tests, the social and cultural dimensions of teacher training, language syllabus design, bilingual education and discourse and genre, to name but a few. He is also known as the scholar who worked on a provisional decoding of the Voynich manuscript and more recently had been developing the tool Text Inspector, which grew out of his work in language testing at Canterbury Christ Church University (1993-2009), Bedfordshire University (2009-2015) and later at the UK Open University, where was Professor of Modern Languages and Linguistics. He was a notable recipient of TESOL's Distinguished Researcher Award in 2014 for his work on eye-tracking and of the British Council's ELTon award for Digital Innovation in 2017 for Text Inspector.

Stephen Bax was perhaps best known in the field of CALL for two papers published in System, his seminal paper, "CALL—Past, Present and Future" published in 2003, and "Making CALL work: Towards normalization”, published in 2006. For the first he was awarded the Elsevier prize for best journal article and both publications proved to be highly influential for a generation of students, practitioners and researchers around the world. He returned to the theme again in "Normalisation Revisited: The Effective Use of Technology in Language Education" in 2011 in the International Journal of Computer-Assisted Language Learning and Teaching. Other published works, which included three authored monographs, marked him out as an academic who championed foreign language education, and encouraged criticality and open-ended enquiry, particularly with respect to the assumed certainties of digital education. Consequently, he was equally adept at pushing the boundaries in relation to new forms of e-research methodology, as was evident in his work on eyetracking, testing and reading. The seven articles collected in this special edition of System aim to commemorate Professor Bax by reflecting on his work and engaging current and future students and 
scholars in critical dialogue with its main concerns, particularly in the areas of the normalization of technology, eye-tracking and teacher training.

Yoon and Gruba’s article, "Evaluating Normalisation: An Argument-based Approach", explores normalisation in the context of blended learning, a commonly advocated pedagogical approach for introducing digital technologies into language teaching. They argue that students are likely to expect digital technologies to be a feature of many language classes in the $21^{\text {st }}$ Century and that an approach that starts outside of the classroom, but which leads to activity in the classroom is likely to be a good fit for such learners. Moreover, while materials in the digital age have been transformed by technology and while teachers are not necessarily proficient programmers, the range of materials, both with respect to product and process that can be created, is very diverse. Materials and processes might also be aligned to some form of standards, but if normalisation is to be achieved effectively, then materials will be constructively aligned (following Biggs) and this is the starting point for this study. The findings showed that while the instructors demonstrated skills for introducing technology into their teaching, there were still areas where they lacked the necessary digital skillset. In the final analysis they show that there is moderate support for normalisation and while this goes some way to support Bax's central thesis, there is a need to promote a better understanding of the constructive alignment with a shift away from focusing on technology to the role that pedagogy plays if it is to be truly achieved.

In "Preparing Preservice EFL Teachers for CALL Normalisation: A technology Acceptance Perspective", Mei explores the important area of teacher education and support in China. While most research on the subject has explored the factors that predict language teachers' uptake of CALL, Mei's study addresses the gap around how these factors connect with current language teacher education programmes. Attitudinal and cognitive differences between preservice teachers at the junior and senior levels in a Chinese university were compared arising from questionnaire data that were analysed through structural equation modelling. The findings suggest that though progress has been made, the preservice programme may need further improvement. Implications arising from the study indicate that there is a need for a more systematic evaluation-based approach to understand the effect 
of teacher education programmes on how trainee teachers use digital technologies in their teaching.

One key implication of the study is a potential framework that may help to align technology, curriculum, and pedagogy more effectively which will be valuable to teacher education policymakers in China.

The section on eye-tracking starts with a useful overview of eye-tracking L2 learner process research from Latif who identified eight areas where this approach has been used: vocabulary processing and learning, listening, syntactic processing, written text production, reading comprehension, computer-mediated communication, oral production, and data validation. In "EyeTracking in Recent L2 Learning Research: A Review of Areas, Issues, and Data Collection”, Latif provides some useful historical background relating to the exploration of eye-tracking, pointing out that whereas early work in this area focused on written text, more recently studies have focused directly on the hidden parts of the cognitive process of language learning. Within the area of vocabulary, the core areas of coverage are: incidental word acquisition, idioms, collocations and morphological processing. Latif highlights that there is a growing interest in the use of dictionaries. A second area of interest is in listening where studies have looked mostly at video data focusing on the use of sub-titles to support listening. Latif suggests that future studies should focus more on current issues in language learning, for example, the role of inductive grammar teaching. Other areas of focus for studies include, writing, reading, CMC, oral production and data validation, but there are few studies in these areas. In writing, translation studies are more common and in reading Bax's work on exploring online reading tests is important. CMC studies have mostly focused on written texts rather than spoken language data. While Latif points out the difficulties of doing such studies he also points out there is a growing trend.

Windeatt and El Ebyary, in what we might see as an answer to Latif, focus their study, "Automatic Feedback on EAP Student Essays", on the topic of feedback for written language. The article explores feedback from an automated written language evaluation programme, Criterion, and tracked what errors the learners focused on and what feedback they read. Stimulated recall and questionnaires were used to understand why they engaged in the practices they did. Feedback on 
writing in general is hard to capture and there are mixed results on its impact. Despite this it is seen as an important feature of classroom practice that learners often ask for more of.

Automated Writing Evaluation software is becoming increasingly important in looking at writing feedback, but so far research has not looked into what areas of feedback writers focus on. The study conducted at a UK university explored the attention to feedback of four learners and used eyetracking software to record how long they focused on particular parts of the feedback as they edited their essays. Data were collected using the eye-tracking software itself as well as recall stimulated by looking back at the recordings of the fixations. Students were asked to try to recall why they focused on particular areas. The results suggest that regardless of the number of errors made in each language area, there was a marked tendency to focus on comments on grammar, and on organisation and development rather than usage, mechanics and style. This focus appeared to be influenced by past educational experience, motivation and writing purpose.

While O'Rourke and Michel focus on eye-tracking software as the core of their study, "What Drives Alignment During Text Chat with a Peer vs Tutor? Insights from Stimulated Recall and EyeTracking", they did so within the framing of the normalisation of Computer-Mediated Communication, which they argue has gone from being an esoteric practice in small corners of academia to a normalised practice, even if not fully normalised in language learning. In applied linguistics text chat has been identified as way of doing speech in an alternative environment, but because of its nature allowing different things to happen. The process of producing written text allows for more reflection, or for 'noticing' to occur, for example. O'Rourke and Michel focus on the topic of alignment where L1 speakers are seen in dialogue to move together in their use of language as they interact. In other articles they have started to explore whether this happened for L2 speakers and this article is a continuation of this work. L2 users do align, but not in the same ways as L1 users and may resist the process for a variety of reasons. It has been found that L2 learners resort more to language that has been primed for them, perhaps staying with language that represents their own L1 rather than moving towards the language of their interlocutor. Most of the research in this area has not focused on naturalistic language contexts and this is what O'Rourke and Michel explore here. Other research, 
apart from their own, has not made use of eye-tracking and here they use it in conjunction with "posttask cued interviews" to explore the phenomenon. They want to see if alignment is more automatic or strategic and governed by priming. Key findings include that the L2 speakers did not align to their interlocutors at the 3-gram and above level, although there was evidence to suggest that further research might explore alignment at one or two word level. However, the learners did align more to their tutors' language rather than other L2 students particularly at lower levels and their gaze did spend more time fixating on tutors' even though the lenths of fixations were not long. In the interviews the students were aware that alignments might occur but could not be specific about what they focused on.

The last two papers were being jointly worked on with Stephen Bax before he died and have been completed by his co-authors for this special edition. In "Using eye-tracking research to inform language test validity and design", Bax and Sathena Chan report on a study which deployed eyetracking to explore the cognitive validity of two level-specific English Proficiency Reading Tests (CEFR B2 and C1). Arising from a mixed methods approach the paper examined the reading patterns from 20 participants relating to six identified types arising from eye-tracking data and a participant self-report checklist and 8 participants who responded to stimulated recall interviews. Two main findings emerged which identified a range of cognitive processes related to different reading item types across two levels, and secondly a series of differences between stronger and weaker test participants' reading patterns on each item type. Particularly from the methodological point of view, implications from the study suggest that it was effective in combining the use of advanced eye tracking technologies with traditional paper questionnaires, and with innovative stimulated recall procedures to identify insights into readers' behaviour when completing high level reading tests.

In the final paper in this special edition, "Researching L2 writers' use of metadiscourse markers at intermediate and advanced levels", Bax, Nakatsuhara and Waller explore data arising from what they refer to as the first large-scale project of the metadiscourse of general second language learner writing. In total they analysed 281 metadiscourse markers in 13 categories, from 900 examination scripts at CEFR B2-C2 levels and employed the online text analysis tool Text Inspector, 
created by Stephen Bax. Findings arising from this novel study indicate that higher level writers deployed fewer metadiscourse markers than those with lower proficiency levels, while at the same time drawing on a wider range of 8 of the 13 classes of markers. Moreover, it was highly significant that analysing the behaviour of whole classes of metadiscourse items alongside individual items themselves revealed new insights into behaviour for learners at these CEFR proficiency levels. For example, it was evident that the more proficient L2 writers in the study deployed significantly fewer metadiscourse markers than writers at lower proficiency levels. Findings appear to contradict some seminal studies in the field and provide new insights into the way discourse develops over time and how discourse is viewed in the wider context of the CEFR.

We hope have these seven papers can be viewed as a fitting testament to Stephen's work, particularly in the intersections between CALL, applied linguistics and teacher development. They represent key themes from his scholarly interests and continue to develop the research work that he pioneered. We hope that this special issue will provide the impetus to others who are interested in taking these themes further in the future. Finally, we would like to thank Stephen's family (particularly Bruce Bax from the University of Newcastle and his son Andrew) and colleagues for their co-operation in producing this edition. 